\title{
On medicine, the arts and sharing the burden
}

$\mathrm{T}$ he patio in front of the Museum of Contemporary Canadian Art on Toronto's Queen Street West was choked with people. Be-tuqued and mustachioed couples stepped in and out of the pools of light while a man in a dark suit polished his recently emptied hors d'oeuvre tray. It was the end of a

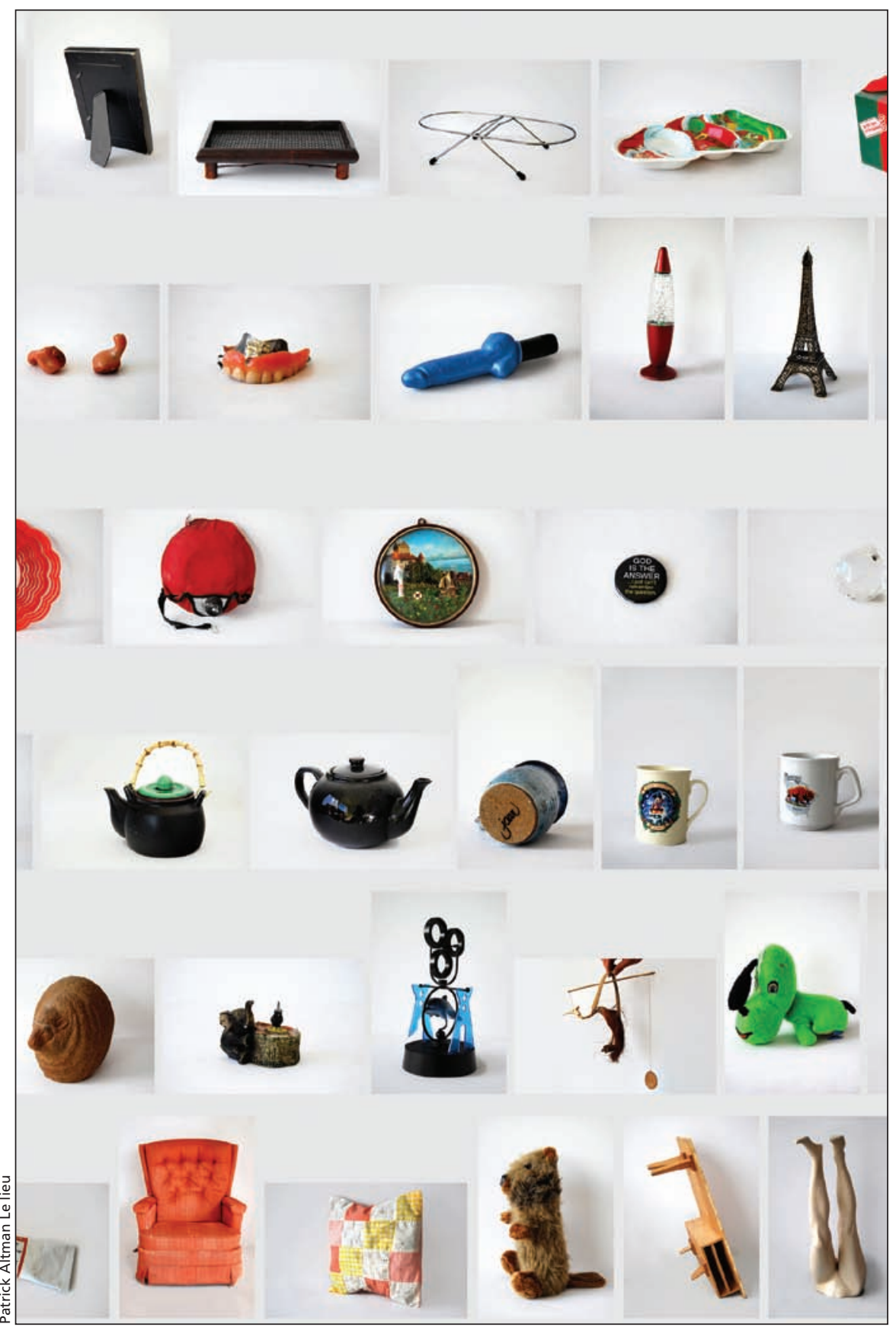

The Burden of Objects - Inventory 1 (diptych), 2009, by Raphaëlle de Groot, digital print, $78 \times 92.3 \mathrm{~cm}+78 \times 53 \mathrm{~cm}$. long day and I had returned to spend a bit more time with an installation by Montréal's Raphaëlle de Groot, which I'd stumbled across a couple of days earlier, when I remembered it was time for the announcement of the Sobey Art Award, for which she'd been shortlisted. Given the size of crowd, I thought my chances of muscling in to see the piece that so interested me was pretty small, so I crossed my fingers for her and continued back to my hotel.

It hadn't immediately stood out to me: it comprised a small glass-topped credenza plus a diptych in which the left panel showed tiny pictures of discarded objects, and the right panel showed a series of quotations from the objects' owners. The credenza displayed stacks of paper, scribbled over in various languages - answers to questions posed by the artist: whether the object held any special meaning, how the object came into the owner's possession, why the owner was letting it go and where it had previously lived.

At first I wasn't sure what had drawn me so powerfully to the exhibit. It wasn't the objects themselves: a pair of eyeglasses, a scorched frying pan, a partial dental plate, a chamber pot, a band saw a plastic thermometer. Perhaps it was the little glimpses of despair: "I have too many photos of myself wearing this dress and looking young and in love." "It destroys everything it touches." "In 2004, on this telephone I received word of my mother's impending death." (Though if it was despair I was drawn to, her suggestion of a dismembered corpse, represented by a tweed jacket stuffed with junk, tied in omentum-like bags of plastic surrounded by tangles of red thread showed that much more obviously.)

I realized afterwards it was the title of the piece that had moved me: Le Poids des Objets? (or, in English translation, The Burden of Objects). The artist recognized that memory - here embodied in material things — can be oppressive. 
Then she went a step further: she exorcised her collaborators' oppression by asking them to tell a story. Much the way doctors do when we ask a patient to talk through a trauma, because we know that putting things into words is a kind of salvation. As Rita Charon wrote recently in the New England Journal of Medicine, "One's experience becomes visible when given form ... Experience without mediation through representation is evanescent, not because it's forgotten, but because without material form - painting, story, poem, it cannot be beheld, and so it's as if it never happened.

I have what some might consider an odd habit of writing poems about old photos of people I find in junk stores. ${ }^{2}$ I think what draws me to the photos is that need to represent experience: in discarding a picture, a person unburdens himself of the story contained within it, but who then speaks for what's been abandoned? I suppose my poems peer out on De Groot from the other side of the looking glass. Either way, I realized it wasn't the visual impact of her piece, but rather her impulse that I found beautiful.

Later that night I looked up to see who had won. Here's what the Sobey award committee said when they gave her the $\$ 50000$ prize: $^{3}$

Through her practice we are called on to be active witnesses, intrigued by what we see, disturbed by what we discover of ourselves and by what is revealed to us in this encounter with art and the artist ... Her work reinforces common values and shared human experiences.

That sounds like there are some lessons for medicine in that.

\section{Monica Kidd MD}

Assistant Professor

Department of Family Medicine

Faculty of Medicine

University of Calgary

Calgary, Alta.

\section{References}

1. Charon $\mathrm{R}$. The reciprocity of recognition - what medicine exposes about self and other. $N$ Engl $J$ Med 2012;367:1878-81.

2. Kidd M. Actualities. Kentville (NS): Gaspereau Press: 2007.

3. Ptashnick V. Raphaelle de Groot wins Sobey Art Award. Toronto Star 2012 Nov. 17. Available: www .thestar.com/entertainment/article/1289143\%20-\% 20raphaelle-de-groot-wins-sobey-art-award (accessed 2012 Nov. 17).

\section{POETRY}

\section{Erasers}

Eradere paginam (Erase the page)

This is the type that most people are familiar with. You rub it against paper and what was written disappears, the grooves on paper a faint reminder of where the pencil once was.

\section{Eradere ut vivere (Erase so as to live)}

"I want to live," she wrote with a feeble hand. So machines hummed on to keep her alive, and she was saved. But today, a few years later, she talks of wanting death, maybe a car running over her as she scooters across the street going from one doctor's appointment to another. Would she regret being saved? Would she still smile, as the afternoon sun peeked at rainy Vancouver?

\section{Noli eradere (Don't erase)}

44 yo female with MS, I glanced at her chart. I asked about her history, medications, surgeries, hospitalization, allergies. But mostly she digressed and told me about her marriage, divorce, daughters. "44-year-old female with MS," her friend had suggested she include on her dating profile. "Is that who I am?"

\section{Eradere ut oblivisci (Erase so as to forget)}

The search for a cure.

Antidepressants, painkillers, surgical removal of a breast. To correct abnormalities - too tall, too short, too fat, too skinny, teeth uneven; too many standard deviations from the mean.

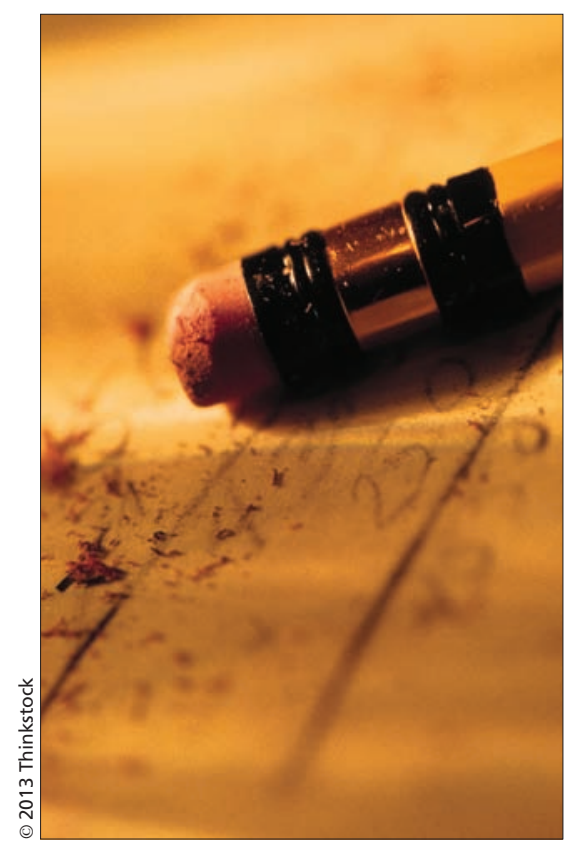

\section{Eradere ut medicare (Erase so as to heal)}

White walls of hospitals: a quiet end, a new beginning. The surgeons cut deeper and deeper and there: his shuddering heart. They rerouted his blood to machines, and I ducked as the first pulse of blood ejected high from the open aorta. They scraped out his calcified valve, sewed in a synthetic one, put the heart back in action, wired together the ribs, and stitched up the skin. After three months, perhaps all that remains of this episode would be the faint squiggly lines of the stitches.

\section{Eradere ut abire (Erase so as to leave)}

A swallowed yawn, or silence that shrouds the rest of the sentence into

\section{Janny Xue Chen Ke}

2nd-year medical student

University of British Columbia

Vancouver, BC

CMAJ 2013. DOI:10.1503/cmaj.121787 